ARTICULO DE INVESTIGACION

\title{
EVALUACIÓN SOCIO-ECONÓMICA DE MANIZALES EN EL MARCO DE LOS OBJETIVOS DEL MILENIO DURANTE EL PERÍODO 2000-2005.
}

\section{Socioeconomic Assessment of Manizales within the Framework of the Millennium Development Goals during 2000-2005.}

Ciro Alfonso Serna Mendoza.

Palabras claves: Objetivos del milenio, evaluación, equidad y género, mortalidad infantil, política de empleo juvenil, sostenibilidad del medio ambiente, pobreza extrema y hambre.

Keywords: Millennium development goals, assessment, equality and gender, children mortality, policy of youth employment, environmental sustainability, absolute poverty and hunger.

\section{Resumen}

El presente artículo es el resultado de la investigación titulada “Evaluación Socioeconómica de Manizales en el Cumplimiento de los Objetivos del Desarrollo del Milenio durante el Período 2000-2005". En dicha investigación se buscaba evaluar socio-económicamente la ciudad de Manizales, en función del cumplimiento de los compromisos internacionales orientados hacia la búsqueda de los objetivos y metas del milenio. La investigación se orientó a presentar una evaluación con un sentido crítico, distinta a los enfoques instrumentales y tecnocráticos, que son los que tradicionalmente dominan los análisis evaluativos. Se buscó aportar un enfoque interpretativo, debido a que éste permite aclarar y comprender las complejidades del proceso de desarrollo, que permiten elaborar reales estrategias de intervención social más adecuadas.

\section{Abstract}

This paper shows the result of an investigation called "Socioeconomic Assessment of Manizales within the Framework of the Objectives of the Millennium during 20002005." The objective of this research was to assess the city of Manizales from the socioeconomic point of view and the achievement of international compromises, oriented to reach the goals of the Millennium project. The research was oriented to present a critical assessment, far from instrumental and technocratic approaches, which is the traditional emphasis in the evaluative analyses. The approach adopted was an interpretative one. This approach allows us to clarify and understand the complexity of the developmental process, which in turn allows us to build real and more adequate strategies for social intervention. ${ }^{2}$

1 Ec; Esp; Mg; Phd. Director Maestría en Desarrollo Sostenible y Medio Ambiente. Un i vers i d a d d e Manizales. DocenteInvestigador. Facultad de Economía y Administración de Empresas. Universidad de $M \quad$ a $n$ i redesom@umanizales.edu.co

2Traducido por Carlos A. Muñoz, integrante grupo de investigación CITERM. -UAM- Revisado por el nativo Kevin P. Guzzo.

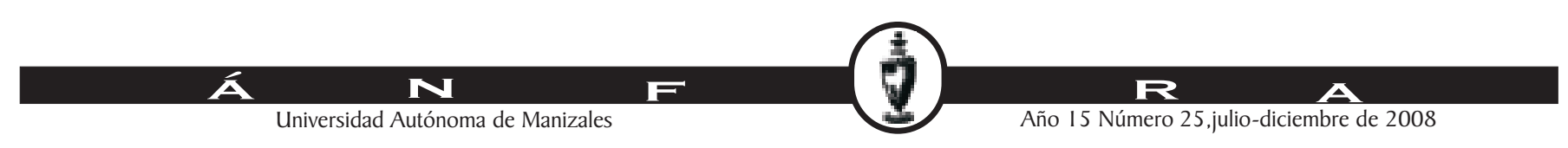




\section{Diseño Teórico - Diagnóstico Actual}

El diagnóstico actual de Caldas y Manizales, frente a los objetivos del milenio ha sido revisado del documento "Análisis demográfico y diagnóstico social de Caldas" durante el periodo 2004 - 2005, elaborado por el DANE, La Secretaría de Integración y Desarrollo Social de Caldas y la Sociedad de Mejoras Públicas.

Dentro de la complejidad de fenómenos que influyen de una u otra forma en el desarrollo de un país o región, las condiciones demográficas constituyen elemento fundamental de análisis, ya que están determinadas por los diferentes factores sociales, económicos y ambientales.

El Territorio caldense con 7.888 Kilómetros cuadrados, tenía una población estimada de $1^{\prime} 146,846$ habitantes en el año 2003 , lo cual representaba $0.7 \%$ de la superficie del país y el 2,6\% de su población. Ello significa una densidad de 145,4 frente a 39,0 personas por $\mathrm{Km} 2$ calculada para el nivel nacional.

De acuerdo con la distribución geográfica en que se ha dividido el departamento en seis subregiones; es posible establecer su distribución espacial, como un indicador de concentración demográfica. Es así como la capital y los cuatro municipios aledaños, que conforman la subregión Centro Sur, cuentan al año 2003 con el 49,2\% de los habitantes, mientras en segundo orden se encuentra el Magdalena Caldense, con $12.4 \%$, correspondiéndole la menor participación al Alto Oriente, con 7,6\%.

Caldas, como Colombia y el resto de países de América Latina, es un territorio que tampoco se ha sustraído al acelerado proceso de transición demográfica, como producto de las vertiginosas disminuciones en los niveles de mortalidad y natalidad en la segunda mitad del siglo XX. Todo esto ha producido un ostensible descenso en la proporción de la población infantil, el abultamiento en la franja de la población adulta y una creciente e importante participación de la población denominada como "Tercera edad ". Prueba de lo anterior, es el aumento en la edad mediana de la población que en Caldas para el año 1999 era de 22,86 años, pasando al año 2000 a 25,77 años y posiblemente en el 2015 llegará a los 30,54 años.

Tanto en Colombia como en Caldas, se evidencian profundos cambios en la formación de uniones y en el ejercicio de la sexualidad no-nupcial de jóvenes y adultos. En Caldas, según resultados del Censo de 1993, como en el resto del país predomina el tipo de familia nuclear, $56,7 \%$, mientras que la familia extendida constituye el $28,0 \%$, la compuesta el $9,2 \%$ y la unipersonal el $6,1 \%$. En Colombia, la familia nuclear para ese mismo año, representaba el $54,9 \%$, la extendida el $30,4 \%$, la compuesta el $7,8 \%$ y la unipersonal el $6,9 \%$.

Si observamos por sexo o género, mientras los jefes hombres tanto en Caldas como en el resto del país, en su mayoría, $52,1 \%$, organizan su núcleo familiar contando con la presencia de cónyuge e hijos, en espacio independiente, las mujeres con sus hijos, en un $31,8 \%$, requieren el apoyo de otras estructuras de parentesco para poder sobrevivir, pero es todavía mayor la proporción de mujeres que viven solas con sus hijos, 37,0\%, muchas veces como expresión de ganancia en autonomía ideológica y económica. Debe por demás tenerse en cuenta, que la jefatura femenina contiene no solo elementos de acceso al poder, sino que incorpora también fenómenos de abandono conyugal, madre-solterismo, viudez y precariedad económica.

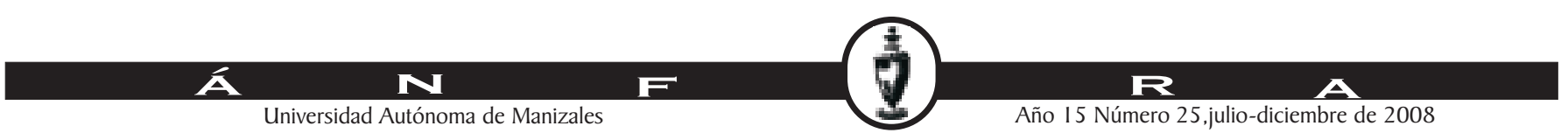


De acuerdo con el número de personas por hogar, el tamaño con más frecuencia relativa en Manizales - Villamaría es el de tres (3) personas, con una participación de $25,8 \%$, lo cual la diferencia de las demás áreas metropolitanas existentes en el país donde la moda se ubicó en la categoría correspondiente a cuatro (4) personas, aunque la capital de Caldas y su vecino municipio antes mencionado, los hogares con un promedio de cuatro (4) personas representaban el $22,8 \%$, seguido por los hogares con dos (2) personas, $16,0 \%$, y con cinco (5) personas, $13,7 \%$.

La distribución de la jefatura de las familias en Caldas, según sexo o género, en los estratos de población registrados por el SISBEN, durante el periodo enero 1994 - junio 2002 , fue de $67.8 \%$ hombres y $32,2 \%$ mujeres. La subregión donde más prevalece la jefatura masculina es la Alto Oriente, $79,9 \%$, seguida por la Norte, 71,7\%, mientras en la Centro Sur se presenta la menor participación, 63,6\%. En Manizales específicamente se reporta que un $38,1 \%$ de la jefatura de familia corresponde al género femenino.

Según el género, es mayor el porcentaje de jefes sin estudio en hombre, $12,0 \%$ frente a las mujeres, 10,6\%. El mayor porcentaje de jefes de familia, con algún nivel de estudios secundarios lo posee la Centro Sur, 27,2\%, seguido por la Occidente Alto, con $26,5 \%$, donde Riosucio tiene la mayor participación respecto a todos los municipios del departamento, 41,4\%, siguiéndole La Dorada, 31,4\% y Manizales, 30,8\%. Llama especialmente la atención, el peso significativo de los jefes de familia con algún nivel de educación superior en Riosucio, 6,9\% y Viterbo, 4,7\%, ya que para el departamento fue de $1,5 \%$ y en Manizales fue del 1,1\%.

En Caldas, de los 154,982 hogares registrados por el SISBEN, el 28,6\% contaban con jefatura femenina; por encima del 30,0\% se colocan Manizales y Villamaría, con el $32,2 \%$. La jefatura femenina es un concepto aún en proceso de construcción, estrechamente asociado con los fenómenos de conyugalidad, ciclo vital de ella y del grupo familiar, capacidad económica, y reconocimiento por parte de ella y de sus parientes, de su aporte monetario y no monetario en la supervivencia del hogar.

Si hacemos referencia al tema Educación tomando como referente global al departamento pero representando la participación de su ciudad capital; según resultados del Censo de 1993, la población de 5 años y más en Caldas, tenía una tasa de analfabetismo de $11,0 \%$, correspondiéndole a las cabeceras (urbano) el $8,4 \%$ y el resto (rural) 15,8\%. La Subregión Centro Sur presentó el menor nivel, 8,0\%, siendo Manizales el municipio con el más bajo porcentaje de analfabetas del departamento. Si se considera la población de 15 años y más, en 1993 la tasa de analfabetismo en Caldas fue de $7,4 \%$, correspondiéndoles a los hombres $8,3 \%$ y a las mujeres el $6,5 \%$. Se presentaron valores extremos, que van desde 3,0\% en Manizales 12,0\% en Palestina.

En cuanto a la proporción de la población de un determinado grupo de edad que reporta asistir a una institución educativa de carácter formal o especial. Caldas en 1993, presentó una tasa de asistencia escolar de $84,6 \%$ para el grupo de 7 a 11 años de edad y de $63,2 \%$ para el grupo 12 a 17 años, siendo en ambos casos mayor la participación de las mujeres frente a los hombres. Por encima del promedio departamental del grupo de 7 a 11 años, se encuentra Manizales, 92,8\%; la cobertura de la asistencia escolar en Manizales fue de $96,2 \%$.

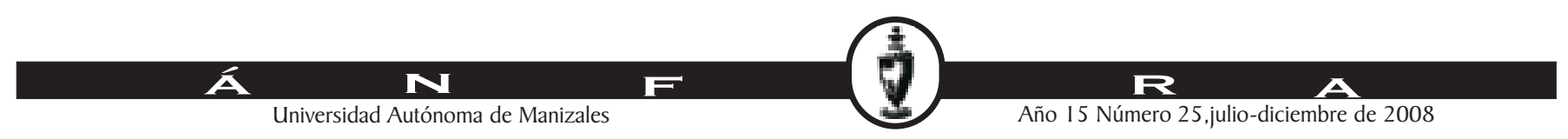


Una de las mayores coberturas en lo que corresponde al grupo de 18 a 25 años, la presenta la subregión Centro Sur con 18,3\%, en donde Manizales con 20,3\%, se encuentra por encima de esta medida promedio. En cuanto a la cobertura de asistencia rural específicamente para el grupo con edades entre 7 a 11 años, Manizales llega a una cobertura de 93,4\% una de las más altas al interior de la subregión Centro Sur.

Si se analiza el promedio de años de educación de la población mayor de 15 años, identificada por el SISBEN en Caldas a 2003, se pudo establecer un promedio de 5.5. años para el departamento, para Manizales es de 6.5 años en promedio superior en promedio por un año. En las zonas urbanas del departamento, como es de esperar, el promedio de años de educación es mayor, para Manizales 7,0 años. Para las zonas rurales de los municipios, el promedio de años de educación, en las personas registradas por el SISBEN, a 2003 fue de 4,2 años; figuran con los mayores promedios Riosucio 5,3, Marmato 5,2 y en un tercer lugar Manizales con 5,0 años en promedio de de años de educación.

Para el año 2003 el promedio alumno/docente de básica primaria en Caldas llegó a 26,8 , en las áreas urbanas 28,6 y 23,9 en las rurales. En el sector oficial alcanzó un promedio de 27,9 y en el no oficial de 20,0. En Manizales se registró un promedio de 28,0. En el área rural, Manizales es reseñado con 27,0. Alumnos por docente.

En relación a la Educación Preescolar, durante el periodo 1991 - 2004 el número de alumnos matriculados en Caldas registró un incremento de $60.0 \%$, al pasar de 13,679 a 21,972 niños, donde la participación de la capital - Manizales - bajó de 59,1\% a $50,2 \%$ y su concentración en las zonas urbanas del departamento pasó de $93,3 \%$ A $79,3 \%$. Por su parte, la matricula en el sector oficial aumentó su participación de 51,2\% a $77,2 \%$.

Respecto a la deserción preescolar, ésta pasó de 10,3\% en 1999 a 8,3\% en 2003, donde en la zona rural fue superior, $13,6 \%$ y $13,4 \%$, frente a la urbana, $9,9 \%$ y $7,3 \%$. Entre los de menor deserción preescolar se destaca Manizales la capital que se ubica por encima del nivel departamental, con el $8,7 \%$.

En cuanto al número de alumnos matriculados en Educación Básica primaria en Caldas, disminuyó 2,0\% entre 1991 y 2004, pasando de 113,640 a 111,356 niños, de los cuales en el primer año antes mencionado el $61,7 \%$ se encontraban en la zona urbana, aumentando su participación $66,3 \%$ en 2004 . Según sectores, el oficial mantiene la mayor proporción, pasando de $92,9 \%$ a $94,1 \%$. En cuanto a la extraedad en básica primaria para Caldas en 2003 , ésta alcanzó $19,0 \%$, correspondiéndole a la precoz $1,8 \%$ y a la tardía $17,2 \%$. Manizales presentó uno de los menores porcentajes, $15,0 \%$.

Durante el año 2000 la tasa de reprobados en básica primaria en Caldas fue de 9,3\%, mientras en Colombia fue de 7,7\%. Entre 1999 y 2003 este indicador en Caldas pasó de $9,7 \%$ a $6,1 \%$. Según municipios, se dio una de las menores tasas en Manizales, 4,5\%. La tasa de repitencia en básica primaria al año 2000 en Caldas alcanzó el 8,0\% y para el 2004 descendió a 4,9\%; entre los que en 2004 presentaron los más bajos niveles, Manizales paso de 5,7\% a 2,9\% entre 2000 y 2004.

Por área, se observa un importante incremento en la matricula rural entre 1991 y 2004 , de $113,2 \%$, mientras la urbana solo aumentó el $13,4 \%$ donde la mayor variación se presentó en las zonas rurales del resto de los municipios del departamento,

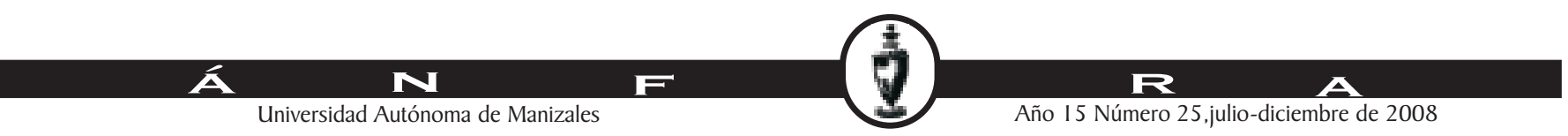


exceptuando la capital, 115,8\%, aunque Manizales también tiene un incremento significativo en sus alumnos rurales de $100,6 \%$. No obstante, debe tenerse en cuenta que en esta oportunidad la comparación se realiza para un intervalo de 13 años, lo que ayuda a explicar la alta variación, sin perjuicio del contraste observado entre el incremento de la matricula urbana y rural, donde ésta última aumenta su participación del $8.8 \%$ en 1991 a 15,4\% en 2004.

Tal como ocurre con la educación primaria, la marcada disminución que se observa en la matrícula no oficial de básica secundaria y media, entre 2003 y 2004 , de -38,2\%, puede obedecer en gran parte al hecho de que para las secretarias de educación, particularmente la de Manizales, algunos establecimientos que vienen siendo considerados en el Formulario C600 DANE-MEN como privados por ser propietarios de sus plantas físicas y cuya personería jurídica tiene tal carácter, para aquellas se consideran oficiales por cuanto la mayoría de la nómina del personal docente es pagada por el gobierno. Asimismo, en lo que corresponde a la distribución urbano - rural se presentan algunas discrepancias en la codificación entre las instituciones antes mencionadas, persistiendo la duda sobre aquellos establecimiento que aunque se encuentran ubicados en zonas rurales, atienden fundamentalmente estudiantes de las zonas urbanas.

La deserción en la zona urbana en Caldas bajó de 8,5\% en 1999 a 6,3\% en 2003; dos municipios, Manizales y la Dorada, presentaron en ambos años los mismos niveles de deserción, $7,5 \%$ y $6,3 \%$. Si se compara la deserción en el sector oficial frente al no oficial en Caldas, tanto en 1999 como en 2003 es superior la del primero, 9,2\% y 7,2\% ante el segundo, $5,2 \%$ y $3,3 \%$. Por parte del sector no oficial, donde este tipo de educación se concentra ante todo en la capital, en Manizales fue del 4,8\% y 3,8\% para los años mencionados con anterioridad.

La tasa de repitencia en la enseñanza básica secundaria y media en Caldas pasó de $5,8 \%$ en 2000 a 5,3\% en 2004, donde la subregión Centro Sur en el primer año antes mencionado registró el mayor nivel, 6,8\%, mientras para el 2004 descendió a 5,9\%. Por zonas urbana y rural, la repitencia en la enseñanza básica secundaria y media en Caldas en 2000 fue mayor en la primera frente a la segunda, de 6,1\% y 4,4\%, en tanto para 2004 la tasa de repitencia rural, 6,8\%, superó a la urbana, 5,1\%. Otros municipios que a 2004 presentaron tasa de repitencia en sus áreas rurales, mayores al 10,0\%, fueron: Chinchiná 22,8\% Palestina 13,5\% y Manizales 10,6\%.

De acuerdo con la Ley General de Educación (115 de 1994) se considera como enseñanza básica en el sistema de educación formal, la comprendida entre el primer grado de básica primaria y noveno grado de la enseñanza media. En Caldas, la tasa bruta de escolaridad para el nivel de enseñanza básica fue de $90,9 \%$ en el 2000 y de $88,7 \%$ en 2003 . Por subregiones, la mayor cobertura educativa en ambos años, la registró la Centro Sur, 102,8\% y 103,0\%, debido fundamentalmente a la tasa que presenta Manizales, 109,3\% y 113,4\%, la más alta del departamento en 2003.

Según el estudio "Las regiones colombianas frente a los objetivos del milenio" elaborado por el DNP/PNUD (octubre 2004), la tasa de asistencia a la educación básica en Caldas, pasó de $73,8 \%$ en 1996 a $86,1 \%$ en 2003 , mientras que a nivel nacional fue de $82,9 \%$ a $88,1 \%$.

En cuanto a las posibilidades de acceso a la educación superior, los resultados de las pruebas del ICFES para Caldas en 2004 permitieron establecer que de los 10,464

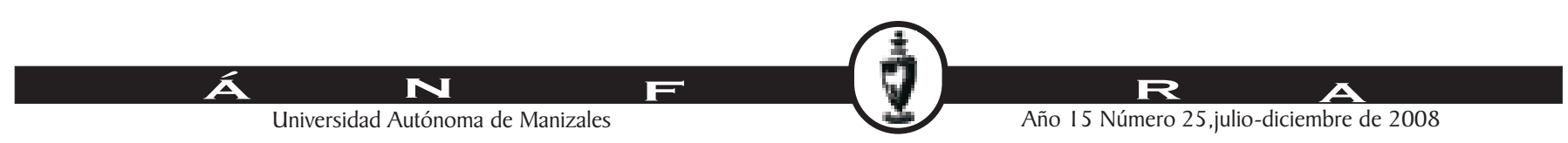


alumnos evaluados, el $48,6 \%$ correspondió a la categoría de rendimiento medio, seguidos por los de rendimiento alto, $21,4 \%$ y bajo, $14,7 \%$. Por subregiones, la Centro Sur fue la única que presentó participación del nivel muy superior, 4,4\%, debido fundamentalmente a que en Manizales el 5,5\% de los estudiantes evaluados se ubicaron en dicha categoría.

En referencia a los objetivos relacionados con el área de la salud; según datos de la Secretaria de Salud de Manizales, la ciudad tiene una tasa bruta de natalidad de 14,8 por cada mil habitantes; esto es, por cada mil manizaleños que empiezan en un año, finalizan mil catorce. La tasa de fecundidad está en 47.1 por cada mil mujeres entre los 15 y los 49 años; es decir, de cada mil mujeres entre estas edades, 47 dan a luz nacidos vivos cada año. Esto parecería bastante adecuado a no ser que el grupo de mujeres de 15 a 19 años presenta una tasa de fecundidad mucho más alta, de 62 nacidos por cada mil, mostrando un fenómeno frecuente de madres muy jóvenes; el $21 \%$ de todos los nuevos manizaleños son hijos de una mujer de 19 años o menos, en otras palabras, uno de cada cinco manizaleños es hijo de mujer adolescente.

La esperanza de vida al nacer está relativamente estable en los últimos años, alrededor de 66,5 años, indicador evidentemente influenciado por un número grande de homicidios en personas jóvenes. La ciudad está libre de rabia humana y canina, sarampión, tétanos poliomielitis, difteria, meningitis meningocóccica, meningitis por haemophilus; se presentan esporádicamente casos aislados de tos ferina; la mayoría de las enfermedades inmunoprevenibles están en área de control, gracias a los altos índices de cobertura alcanzados, superiores estos al $95 \%$ en todos los biológicos. Se ha presentado un número importante de casos durante los últimos años de tuberculosis y VIH/SIDA, y sífilis congénita. Con alguna frecuencia se presentan brotes epidémicos de pediculosis (piojos) y varicela.

La tasa de mortalidad general es de 5,85 por cada mil manizaleños; es decir, de cada mil personas que empiezan en un año, mueren 5,8 , esta tasa ha venido reduciéndose con los años. En cuanto a mortalidad infantil, durante el 2002 fue la cifra más baja de los últimos tres años, hallándose en 11,3 por cada mil nacidos vivos; es decir que de cada mil manizaleños que nacen vivos, 11,3 mueren durante el primer año de vida.

El análisis de la morbilidad y mortalidad materna es una de las actividades más importantes para evaluar el estado de salud de una población y, en consecuencia, la Organización Mundial de la Salud, al igual que distintos organismos internacionales en el campo de la salud, han mostrado en las últimas décadas, un interés especial en el estudio de los problemas de la mujer y en la disminución de la mortalidad materna.

El aborto fue la primera causa de morbilidad materna encontrada en el estudio, con $6.5 \%$ del total de egresos obstétricos. El aborto séptico aportó $13.3 \%$ del total. Los trastornos hipertensivos fueron la segunda causa de morbilidad materna, con $4.2 \%$ del total de egresos obstétricos. La preclampsia ${ }^{3}$ grave y la eclampsia ${ }^{4}$ aportaron un importante $28.8 \%$ al total de trastornos hipertensivos durante el embarazo. La amenaza de parto pretérmino (APP) fue la tercera causa de egresos, con $1.7 \%$ del total de mujeres que requirieron hospitalización.
3 Condición caracterizada por presión sanguínea alta, presencia de proteínas en la orina e hinchazón (edema) debida a la retención de líquidos provocada por el embarazo.

4 Afección que se presenta en la última etapa del embarazo, parto, y en el período inmediatamente posterior al parto. Se manifiesta como una complicación de la preclampsia y se caracteriza por la presencia de convulsiones. Los casos graves pueden llevar al coma o incluso a la muerte.

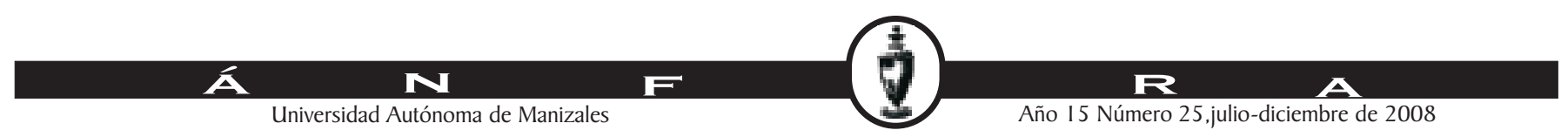




\section{El Caso de Manizales}

\section{Planteamiento y Formulación del Problema.}

En septiembre del año 2000, en la denominada cumbre del milenio los jefes que representan los distintos gobiernos del planeta se comprometieron a cumplir una serie de objetivos encaminados a luchar contra la pobreza, mejorar la educación, la salud y el medio ambiente. Dichas metas deberán superarse para el año 2015. Entre las metas que se acordaron están las siguientes: Erradicar la pobreza extrema y el hambre, el indicador será reducir a la mitad entre 1990 y 2015, el porcentaje de personas con ingresos inferiores a 1 dólar por día, reducir a la mitad el porcentaje de personas que padecen hambre; la segunda meta es lograr la enseñanza primaria universal, es decir velar porque para el año 2015, los niños y niñas puedan terminar un ciclo completo de enseñanza primaria; la tercera meta es promover la igualdad entre los sexos y la autonomía de la mujer. Eliminar las desigualdades entre los géneros en la enseñanza primaria y secundaria, preferiblemente para el 2005, y en todos los niveles de la enseñanza antes de fines del 2005; la cuarta meta será reducir la mortalidad de los niños, reducir en dos terceras partes la mortalidad de los niños menores de 5 años; la quinta meta será mejorar la salud materna en tres cuartas partes; la sexta es combatir el VIH/SIDA, el paludismo y otras enfermedades. Haber y comenzado a reducir, para el año 2015, la propagación del VIH/SIDA y de otras enfermedades; la séptima garantizar la sostenibilidad del medio ambiente. Incorporar los principios de desarrollo sostenible en las políticas y los programas nacionales e invertir la pérdida de recursos del medio ambiente, reducir a la mitad, para el año 2015, el porcentaje de personas sin acceso al agua potable y haber mejorado considerablemente, para el año 2020, la vida de al menos 100 millones de habitantes de tugurios; la octava es la de fomentar una asociación mundial para el desarrollo. En cooperación con los países en desarrollo, elaborar y aplicar estrategias que proporcionen a los jóvenes un trabajo digno y productivo.

Estas metas, son los compromisos que al nivel de naciones se adquirieron en el año 2000. Manizales, sin embargo, padece múltiples problemas sociales y económicos, para lo cual se hace necesario conocer cómo está la situación con respecto a los objetivos del milenio.

En Manizales se observa que la proporción de mujeres es mayor que la de los hombres, pero no con esto queriendo decir que haya equidad entre géneros. A pesar de que la vinculación de la mujer en el contexto laboral ha venido en aumento, este logro no es muestra de una distribución homogénea en la representación de las mujeres en las esferas administrativas y de poder.

Por el contrario, su alcance ha dependido de las diferencias socioeconómicas de forma tal que sólo un reducido grupo son partícipes de estos avances. En Manizales las mujeres con más baja calidad de vida, enfrentan con mayor rigor las consecuencias de la pobreza, la desigualdad y la violencia, por tanto después de 3 décadas de avances importantes persisten condiciones de inequidad de género y hay que trabajar en torno a las enormes diferencias que aún existen entre los salarios de las mujeres y los de los hombres, en la valoración hay diferencias para unos y otras en su contribución al desarrollo; en las diferencias en el logro obtenido de la educación y en cómo la pobreza también discrimina por género.

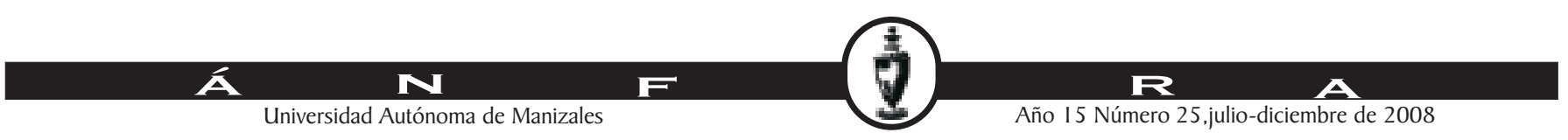


Se observa, además, que la estructura de la población tiende a estancarse y presenta concentración en la población urbana menor de 24 años, con un agravante, la desaceleración de la tasa de crecimiento económico la cual pasó de $2.1 \%$ en el período 1973 - 1985 a 1\% en la actualidad; se observa que hay una excesiva concentración poblacional en los estratos bajos ( 1 y 2 ), mientras que los estratos altos presentan muy bajos crecimientos.

En cuanto a la cobertura de servicios públicos se observa que en la ciudad es buena, lo que no garantiza que las necesidades básicas estén cubiertas adecuadamente. En lo que a necesidades básicas insatisfechas se refiere, el porcentaje de hogares y de personas es el doble en el campo que en las ciudades.

La proporción de hogares y personas en condiciones de miseria es 3 veces mayor en el campo; a su vez la dependencia económica y el hacinamiento crítico son las variables predominantes en las Necesidades Básicas Insatisfechas (NBI).

Manizales aporta el 1.2\% de los ingresos de los hogares en el país y aporta el $16.9 \%$ de los ingresos de los hogares de las ciudades intermedias. El ingreso promedio por hogar es más bajo que en las ciudades intermedias e inferior a Pereira, Tunja, Pasto y Armenia tanto para los grupos de hogares de más alto como de más bajo ingreso.

Durante los últimos siete años la matrícula sólo ha aumentado en cerca de 1000 estudiantes. El 23\% de los estudiantes se desplazan entre comunas para llegar a sus sitios de estudio; este fenómeno ha originado la sobresaturación de las comunas 3 y 8 y la desprotección de las comunas 5 y 10 . Se observa además, que un gran porcentaje de la población entre los 4 y 19 años no es atendida por el sector público, es decir el gasto público es inequitativo ya que la mayor proporción del gasto se destina a los hogares con mayores ingresos, mientras que la menor proporción se orienta a los hogares con menores ingresos.

\section{Fundamentación Teórica.}

\section{La Noción de Evaluación.}

Para saber si los objetivos propuestos por los proyectos de desarrollo social lograron el impacto y los resultados esperados, es necesario recurrir a la evaluación, ya que ésta es una herramienta administrativa "un proceso organizado y enfocado a la acción, para mejorar tanto las actividades actuales como la planificación y programación para la toma de decisiones" ${ }^{5}$.

La evaluación de los programas de desarrollo social es un factor que incide notablemente en la calidad de vida y especialmente aquellos programas que desarrollen acciones sociales por quienes las ejecutan, sea desde las organizaciones de la sociedad civil, como los diferentes instituciones gubernamentales que motiven el desarrollo social de la región. La urgente necesidad de evaluar las acciones destaca el hecho que los investigadores, los evaluadores están desprovistos de definiciones conceptuales y/o herramientas básicas que permitan asumir la tarea de evaluar. Algunos autores citan conceptos de evaluación como: "Proceso orientado a determinar de la manera más sistemática y objetiva posible, la pertinencia, la eficacia y el impacto de determinadas actividades" ${ }^{6}$.
5 ORTIZ PINILLA, Nelson. Diseño y Evaluación de Proyectos. Bogotá. Junio 2000.

6 ORTIZ PINILLA, Nelson. Evaluación una herramienta para el fortalecimiento Institucional. Bogotá. Junio 2000. Pág. 45.

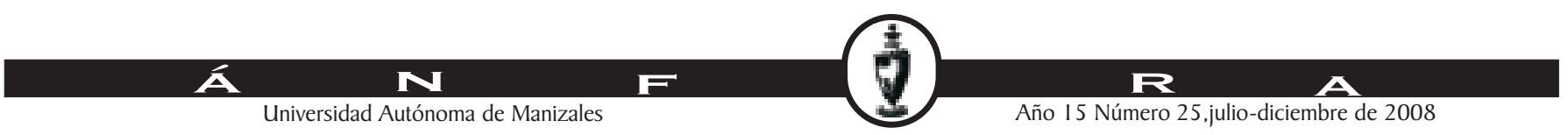


Estos conceptos apuntan sobre cuál es el resultado de su trabajo, de tal manera que puedan mejorar sus prácticas, cuestionar su progreso y mostrar el impacto que ha tenido y las expectativas de las personas a las que se quería llegar.

Estos son conceptos globales para resultados globales pero Peter Oakley, tiene una visión muy diferente sobre lo que es la evaluación; según este autor "Mas que dar por hecho las miradas de los otros, muchas veces implícitas incorporadas en lo que se considera como textos autoritarios, es importante sacarlas de sus pretensiones y resaltar sus parcialidades, como el primer paso en la construcción de acciones con propósito" ${ }^{7}$.

Este concepto se basa de acuerdo a la visión que se quiere dar e identificar la información de tal manera que nos permita conocer los resultados y comprender lo que está sucediendo y a dónde queremos llegar.

Para Peter Oakley existen dos (2) aproximaciones acertadas hacia la evaluación.

\section{Enfoque Instrumental y Tecnocrático}

La evaluación en este sentido busca resultados de las entidades que se preocupan por el desarrollo social; por eso, se hace necesario examinar programas sociales, de esta manera se pueden detectar los problemas y/o fortalezas pertinentes de las organizaciones en pro del bienestar social.

Las evaluaciones de este tipo se asume que la cuantificación se logra a niveles cuando los niveles de subjetividad sean menores. En este punto se dará cuenta si los objetivos trazados en dichos proyectos, se están alcanzando o se hace necesario cambiar algunos objetivos para alcanzar los resultados, a los cuales se quiere llegar con las realizaciones de dichos proyectos.

En estos momentos cuando existe una mayor incertidumbre que generalmente acompaña a estas evaluaciones, ésta se irá desapareciendo, porque cuando se conoce la información y sabemos cómo aplicarla, ya que estos datos reflejan la confianza y calidez a la cual se quiere llegar con la evaluación.

En este sentido, se convierte en una herramienta usada en un intento de detectar y hacer cambios en los programas, y de realizar decisiones pertinentes sobre las políticas que se están llevando a cabo dentro de cada institución, a demás de percibir las falencias o irregularidades en los lugares de impacto en las realizaciones de los proyectos de desarrollo social.

La evaluación debe ser hecha por personas que estén ajenas al proyecto (agente externo), para que los resultados sean más objetivos y confiables; algunos aspectos que debe tener en cuenta el agente externo al evaluar el proyecto es el de percibir en el ambiente algunas anomalías que obstaculicen el buen desarrollo del proyecto evaluado.

Algunos objetivos son poco claros y abstractos, los cuales dificultan su medición, por eso se buscan indicadores más apropiados y más eficaces para el desarrollo social.
7 OAKLEY, Peter et al. Asuntos perspectivas futuras en la Evaluación del Desarrollo Social.

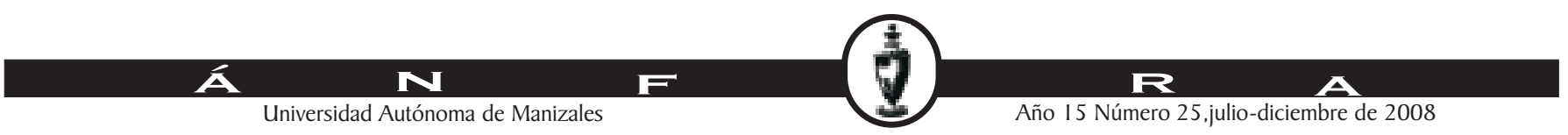


La evaluación trata de ofrecer principios generales que puedan servir de ayuda y de resaltar aspectos que puedan estimular los proyectos en la búsqueda de resultados óptimos, tanto para la comunidad beneficiada como para la organización gestora.

\section{Enfoque Interpretativo}

Este enfoque de la evaluación según Peter Oakley, se refiere a la forma como se hace frente y se comprueba la legitimidad y la autoridad del proyecto ante aquellas personas que consideran ser expertas en el tema sobre el cual se está investigando; además que ayuda a tener una idea más clara acerca de lo que se está haciendo o se hizo.

A este enfoque interpretativo no se le escapa nada ya que está orientado primordialmente a la "reconstrucción". Esta estructura consiste en que el sujeto es quien construye su realidad y nada le es dado, es decir que se debe comenzar de cero en la realización de la investigación.

Esta forma de interpretación ha sido criticada ya que la acusan de desbaratar las explicaciones que ya han sido aceptadas con anterioridad, por esto se ha creído en su orientación negativa.

Aunque todo lo dicho anteriormente lleva a pensar que tiene desventajas; el enfoque interpretativo tiene una gran trayectoria y ha sido utilizado para aclarar y comprender las complejidades del proceso de desarrollo y ha dado bases sobre las cuales se han construido estrategias de intervención social más adecuadas.

El enfoque interpretativo de la evaluación asume que las evaluaciones nunca son neutrales y que tratan fundamentalmente sobre los controles, dirección y recursos.

Los discursos públicos acerca de desarrollo social de los políticos algunas veces disfrazan otros intereses y otras intenciones muy diferentes a las que se le dicen a la comunidad; engañándolos y prometiendo con sus proyectos de desarrollo social el tan anhelado "bien común" trayendo con esto solo pérdidas en términos de recursos. Todo esto es lo que el analista interpretativo intenta descubrir en tantos proyectos que se hacen hoy en día, los cuales solo traen beneficios personales y no colectivos.

El analista basado en un enfoque interpretativo busca develar la realidad de las cosas, la verdad en cada frase y en cada hecho señalado en el proyecto.

\section{Niveles de Evaluación Interpretativa}

La misión principal del enfoque interpretativo es referirse al asunto del poder. Para esto existen unos niveles:

El Proyecto: La finalidad de este nivel es señalar cómo se hace la distribución de los recursos e identificar a las personas que han podido hacer uso de estos, para su beneficio personal o de un determinado grupo y no para la comunidad o sector para el cual fueron establecidos. Ejemplo: mujeres pobres, trabajadores sin tierras.

Gerencia de Proyectos: El objetivo principal es exponer las formas en que los procesos de localización de recursos son manipulados por "consideraciones irracionales", relacionadas con intereses y valores seccionales. Un objetivo de este tipo

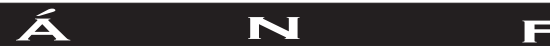

Universidad Autónoma de Manizales 
de evaluación es sacar a la luz la corrupción, el paternalismo, el nepotismo; a medida que se descubren los fraudes y los tapujos que esconden la "mala práctica" del poder, el escenario se recompone para la elaboración de estrategias más honestas, justas e igualitarias. Este tipo de evaluación sobre la administración de proyectos pretende entender cómo se negocia el orden en la organización, bajo la asunción de que las reglas y regulaciones que gobiernan la jerarquía, los procedimientos, las técnicas de monitoreo y registro, no son estáticas o inmutables y pueden ser manipuladas por gente particular con intereses particulares. También pretende descubrir las fuentes de tensión y desacuerdo dentro de la organización, de tal manera que éstas pueden ser removidas y una cultura organizacional que trabaje por un mismo ideal pueda ser patrocinada. El objetivo de tal evaluación será el mejoramiento de las habilidades políticas de aquellos que manejan tales organizaciones, para equiparse con las habilidades necesarias para controlar más efectivamente.

El Ambiente del Proyecto: a este nivel existe la necesidad de entender el contexto sociopolítico en el cual se está trabajando de manera que sea más eficiente la consecución de los recursos así como ganar reconocimiento y buenos resultados. Esta evaluación no debe ser considerada como previa al proyecto, ya que debe ser incluida en todas las etapas.

El planificador de proyectos no llega al proyecto libre de bagaje teórico e ideológico; debe haber estructurado categorías a través de las cuales interpreta el mundo, un rol del evaluador interpretativo es explorar en la naturaleza de este bagaje.

La evaluación interpretativa puede clarificar los límites que existen para la comprensión, puede aproximarse críticamente a la práctica y pueden ayudar a encontrar el camino adecuado hacia adelante.

\section{Resultados de la Evaluación}

\section{Pobreza extrema y hambre}

Los Objetivos del desarrollo del Milenio contemplan reducir a la mitad entre 1990 y 2015 el porcentaje de personas con ingresos inferiores a 1 dólar.

Entre los múltiples retos que enfrenta Manizales, se encuentra la reducción de los altos niveles de desempleo que la afectan (desde 1999 tasas superiores al 20\%). Un aspecto de gran preocupación tiene que ver con la ampliación de la brecha entre la demanda de empleo y la oferta laboral, que se viene presentando desde 1998. La demanda de empleo se deterioró a raíz de las dificultades económicas de los empresarios y empleadores en general, y la necesidad de mejorar la productividad. Por otra parte, la oferta laboral empezó a incrementarse de manera acelerada como resultado de dos situaciones: una mayor motivación por parte de las mujeres a trabajar, en respuesta a la propia crisis, y la inserción en el mercado laboral de miembros de la familia, distintos del jefe de hogar, con la intención de compensar la caída en los ingresos familiares.

En síntesis, la reducción del número absoluto de pobres (NBI) por su aumento por línea de pobreza y la agudización de la concentración del ingreso, son tres características del desarrollo social colombiano, de ahí que el modelo de desarrollo y la política económica deban tener como una de sus prioridades la generación de empleo productivo y de ingresos de amplios sectores de la población. Por consiguiente, se requiere ofrecer un

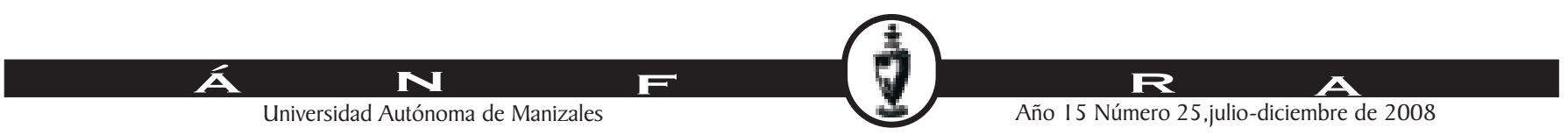


mayor perfil a la política social en todas las instituciones estatales y ser más exigentes con la aplicación y los indicadores de la política social. Y es de gran importancia llegar a acuerdos para reformar y modernizar al Estado a fin de colocarlo inequívocamente al servicio de la superación de la pobreza.

Observando las características de la oferta y demanda laboral, se encuentra que la fuerza laboral de Manizales se caracteriza por ser más masculina que femenina, 53\% y $47 \%$ respectivamente. El 70\% corresponden a personas entre los 25 y los 55 años de edad. El 19\% tiene edades que oscilan entre 18 y 24 . El $8 \%$ supera los 56 años y el $4 \%$ son personas entre 12 y 17 años de edad. Con respecto a su nivel educativo sobresalen los bachilleres ( $30 \%$ de la fuerza laboral), seguidos de quienes no han terminado sus estudios secundarios ( $24 \%$ ). El $26 \%$ sólo alcanzó el nivel primario de educación, mientras que únicamente el $2 \%$ no tiene escolaridad alguna. El $18 \%$ de la fuerza laboral tiene algún nivel de educación superior. Los empleados de la ciudad tienen en promedio 9,1 años de estudios, es decir, hasta 4 o año de bachillerato, lo que la ubica como la quinta, después de las cuatro grandes ciudades del país, con mayor escolaridad entre su población ocupada.

Enseñanza primaria: Se evalúa si los niños y niñas pueden terminar un ciclo completo de enseñanza primaria.

Una baja deserción en primaria (disminución del 3\% en cada grado) en el municipio de Manizales, o lo que traduce que en el $1^{\circ}$ solo 3 de cada 100 niños y niñas que ingresan a estudiar no alcanzan a terminar el año. Si comparamos con el resto del departamento en el cual se detecta una deserción en primaria del $11 \%$, reflejado en la disminución promedio anual de matrícula en cada grado de primaria del $11 \%$. O sea que en el primer grado, 11 de cada 100 niños y niñas que ingresan a estudiar no terminan el año, y en este mismo porcentaje disminuyen las matriculas en la educación primaria por año. Las razones pueden ser muchas y tendrían que investigarse más detalladamente. De lo anterior se puede deducir que en la ciudad de Manizales se ha incrementado en los últimos años el número de niños y niñas que terminan su primaria y que respecto al departamento de Caldas, Manizales tiene un excelente manejo de la deserción en la educación primaria.

- $\quad$ En Manizales el 9\% de los que ingresan al sistema no termina la primaria, el $19 \%$ no termina la secundaria y el $33 \%$ no logra culminar la media y en el resto del Departamento el $34 \%$ de los que ingresan al sistema no termina la primaria, el $57 \%$ no termina la secundaria y el $65 \%$ no logra culminar la media. Este indicador refleja que Manizales respecto al resto del departamento, termina la primaria $25 \%$ más niños.

- La matrícula de la zona urbana representa el 92\% en Manizales. La participación de la matrícula rural disminuye considerablemente al avanzar los grados. En $1^{\circ}$ la matrícula rural representa el $12 \%$, en $6^{\circ}$ el $8 \%$ y en $11^{\circ}$ el $4 \%$ y la matrícula de la zona urbana representa el $62 \%$ en el resto del departamento. La participación de la matrícula rural disminuye de manera importante al avanzar los grados. En $1^{\circ}$ la matrícula rural representa el $53 \%$, en $6^{\circ}$ el $29 \%$ y en $11^{\circ}$ el $18 \%$. Es claro que la mayor parte de la deserción de primaria corresponde a la zona rural, sin embargo se aprecia el mismo problema en secundaria y media en ambas zonas. El aumento de matrícula urbana junto a la

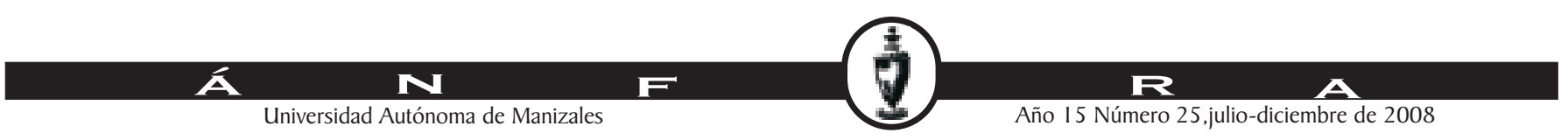


fuerte disminución de la rural en $6^{\circ}$ indica desplazamiento de zona rural a urbana a adelantar estudios de secundaria.

Manizales tiene buenos métodos o medios aplicados en la educación primaria y que puede mejorar para que la deserción en primaria sea del $0 \%$ en el 2015, por el momento esta ciudad se acerca en gran medida a cumplir con los objetivos del Milenio hasta el año 2005.

Mortalidad infantil: Se evalúa si se reduce la mortalidad infantil, se mejora la salud materna, paludismo y otras enfermedades.

La mortalidad infantil es un indicador de la situación social y económica de las familias y las comunidades, porque refleja el nivel educativo de las madres, el poder de compra del hogar para adquirir alimentos, el acceso a los servicios médicos, así como el acceso a los servicios públicos de agua potable y alcantarillado. Así mismo, la mortalidad infantil depende de otros factores como el cuidado prenatal y el estado nutricional de la madre durante el embarazo, el peso del niño al nacimiento, el tipo de nacimiento, la edad de la madre, el orden de nacimiento del niño en la familia y el intervalo entre hermanos; si el niño recibe o no lactancia materna, si le colocan las vacunas contra varias enfermedades en las dosis recomendadas, el conocimiento de la madre sobre los síntomas de gravedad que presente el niño y la decisión y posibilidad de llevarlo al médico.

La mortalidad de los niños de uno a cuatro años también depende de la situación socioeconómica del hogar, así como de la mayor exposición del niño a factores ambientales.

Al terminar su período de lactancia y al iniciar su aprendizaje para gatear y caminar, estos niños quedan más expuestos a adquirir infecciones y a sufrir accidentes. Por ello mueren más de accidentes, infecciones respiratorias agudas, infecciones intestinales y avitaminosis.

La tasa de mortalidad infantil en Manizales en 1993, fue del $29.7 \%$, por encima de Medellín con el $23 \%$, Cali $26.7 \%$, Bucaramanga $24.5 \%$ y muy cercana a la de Armenia $29.4 \%$, Pereira $30.9 \%$ y Bogota $29.9 \%$.

Teniendo en cuenta los datos anteriores, Manizales es de las principales ciudades del país con índices altos de mortalidad infantil, por lo tanto hay que analizar en detalle las causas que ocasionaron este índice tan alto y buscar las estrategias para disminuirlo.

Las principales causas de mortalidad infantil son:

- Sepsis bacteriana del recién nacido

- Infecciones respiratorias agudas

- Malformación congénita del corazón

- Trastornos relacionados con duración corta de gestación y bajo peso al nacer.

- Enfermedades infecciosas intestinales

- Deficiencias nutricionales

- Malformaciones congénitas sistema osteomuscular.

- Hipoxia intrauterina

Desde 1998 hasta 2004 el número de casos de mortalidad infantil en la ciudad de

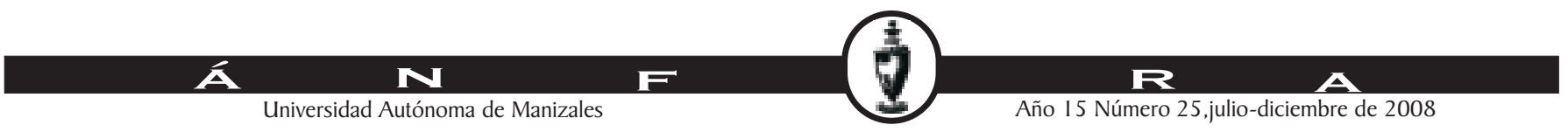


Manizales ha pasado de 74 a 57, es decir, se ha evitado la muerte de 17 niños. La mortalidad infantil se ha disminuido en un $29.8 \%$.

Según los indicadores anteriores Manizales ha disminuido el nivel de mortalidad infantil en un bajo porcentaje que no es el esperado para cumplir la meta establecida por los Objetivos del Milenio. Por lo tanto debe mejorar sus políticas de acción e implementar nuevos proyectos para disminuir la muerte en los niños menores de un año, tales como:

- Fomentar el nivel de educación en las madres informándolas sobre las herramientas técnicas y científicas de bajo costo para prevenir, detectar y resolver la mayor parte de los problemas de salud de la mujer y los niños.

- Ampliar la cobertura, oportunidad, suficiencia y calidad en la vacunación a los niños y las madres.

- Implementar el monitoreo del embarazo desde etapas tempranas, para detectar precozmente condiciones de riesgo o alteraciones en el curso de la gestación que permitan, con un adecuado manejo, reducir los riesgos para la salud de la mujer y los hijos.

- Disponer de la tecnología apropiada para la atención obstétrica esencial, básica e integral y para el manejo de las complicaciones que puedan ocurrir dentro del parto y el posparto.

- Crear nuevas estrategias de planificación familiar que lleguen directamente a la población requerida, especialmente a los adolescentes.

Sostenibilidad del Medio Ambiente: Sí se incorporan y aplican principios del desarrollo sostenible en las políticas y programas municipales.

En Manizales en estos últimos cinco años se ha pugnado más a fondo por fortalecer lo ambiental. "Recordemos que lo ambiental comprende el aire, el agua y el terreno" se han llevado a cabo diversos programas que han orientado la gestión ambiental del municipio para que así se asuma verdaderamente un liderazgo en la gestión y ejecución de acciones y proyectos para la conservación de los recursos naturales. Dentro de estas acciones se ve ya la ejecución de programas tales como:

El Fortalecimiento Institucional Ambiental, que como su nombre lo dice tiene como propósito fortalecer a la administración municipal para que en coordinación con las instituciones gremiales y sociales desarrolle la dimensión ambiental en correspondencia con las funciones y competencias contenidas en el artículo de la ley 99 de 1993. Esta propuesta consignada dentro de la planeación estratégica del departamento se ha llevado a cabo en la mayoría de localidades de la ciudad, se ha realizado acciones tales como el fortalecer las diferentes dependencias de la administración municipal para coordinar la planificación y gestión ambiental en el área de su jurisdicción. Definir y aplicar incentivos económicos y tributarios, entre otros, para quienes protejan y conserven los recursos naturales. Fortalecer y poner en marcha el sistema de información ambiental del municipio. Aplicar los diferentes mecanismos de coordinación interinstitucional para lograr mayor eficiencia en las actuaciones ambientales que se desarrollen en el territorio municipal.

Como Manizales es una ciudad que está ubicada en una zona de alto riego, ya que nos encontramos a escasos cuarenta y cinco minutos del nevado del Ruiz y además de esto el paso de algunas fallas geológicas por algunas localidades de la ciudad, y anexándole el tipo de clima que caracteriza esta zona del país, es de lógica que se implemente una

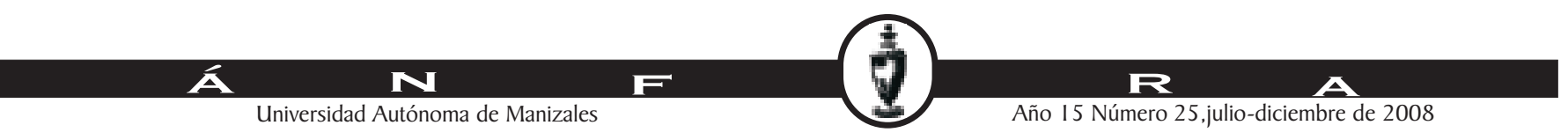


campaña de Prevención de emergencias y desastres que permita manejar adecuadamente las condiciones de vulnerabilidad física frente a las amenazas naturales; disminuir las zonas de riesgos indebidamente ocupadas y afrontar la ocupación del territorio con el conocimiento de las condiciones de actitud del suelo y las características ambientales y ecológicas privilegiando el derecho a la vida. Los gobernantes de esta ciudad no han dejado pasar esto por alto ya que han expedido y han aplicado todas las medidas de prevención tendientes a la protección del aire, del agua, del suelo y sobre todo de las vidas humanas, y así generar una cultura de respeto de las condiciones naturales del terreno como base del crecimiento municipal y del desarrollo de todas las actividades sociales, económicas y productivas. Estos gobernantes han acudido a la reubicación de viviendas localizadas en zonas de alto riesgo por deslizamientos, entre otros. Con esto se han visto en la obligación de construir obras de defensa y estabilidad de taludes; y paralelamente, desarrollar programas de educación para que las conserve y las mantenga en estado funcional óptimo.

Es también de gran relevancia saber que en la ciudad vivimos con una buena red de servicios públicos, así pues la alcaldía se ha llevado el propósito de desarrollar y reglamentar un sistema de saneamiento básico urbano y rural, mediante el fortalecimiento de la calidad y cobertura de los servicios públicos domiciliarios en especial de acueducto y alcantarillado, tratamiento y disposición integral de los residuos sólidos, líquidos y control de fuentes o vectores de enfermedades. Y así con esto poder implementar sistemas de potabilización de aguas en todos los acueductos rurales, posibilitar a los hospitales el acceso a las vías públicas, infraestructura de transporte y demás espacios públicos, y hacer efectivos los derechos constitucionales de la vivienda y los servicios públicos domiciliarios. Atender los procesos de cambio en el uso del suelo y adecuarlo a áreas de interés común, procurando su utilización racional en armonía con la función social de la propiedad a la cual le es inherente una función ecológica que busque el desarrollo sostenible, fortalecer aquellos programas orientados a que los servicios de energía, aseo y telecomunicaciones cubran todo el territorio municipal y que garanticen la presentación eficiente y de óptima calidad de los servicios públicos domiciliarios.

Política de empleo juvenil: Si los jóvenes tienen acceso a un trabajo digno.

Según los cálculos de las encuestas de hogares urbanos, en 1996 sumaron 703 mil las personas desocupadas en el país, de las cuales 10 mil estaban entre 12 a 14 años y 131 mil entre 15 y 19 años. El 2,7\% de ese total de desocupados vivían en Manizales. En estas cifras no figuran los niños y niñas que se ocupan en la prostitución, ni aquellos que realizan trabajos forzados en largas jornadas y que cada vez se denuncian con mayor frecuencia desde los medios de comunicación y desde la Defensoría del Pueblo y Bienestar Familiar. Tampoco se contabilizan quienes acaban de llegar con sus familias en condición de desplazados por la violencia y circulan por las ciudades en busca del sustento.

El peso específico de la población en edad de trabajar (PET) sobre la población total (PT) mantiene cifras relativamente estables en Manizales, con el 78\% (un poco más de 284 mil personas) desde 1984 hasta 1996.

Específicamente, en el grupo 12-14 años (aquel que sirve de referente más inmediato

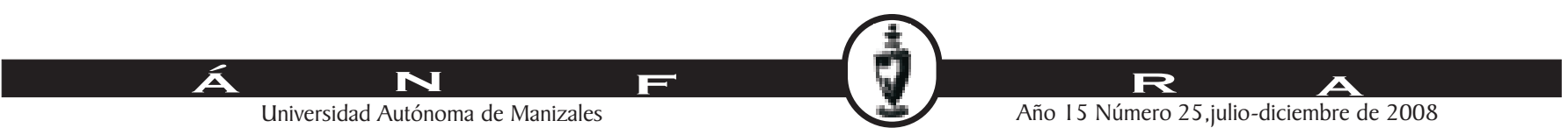


para estudiar el trabajo infantil) se mantiene una participación del $1 \%$ en el total del desempleo. Pese a que las cifras absolutas no son muy elevadas ( 9 mil niños buscando trabajo en las zonas urbanas de Colombia en 1996, y 500 en Manizales y Pereira) ellas sí comportan el drama de una sociedad que no solamente no es capaz de evitar el trabajo infantil, sino que acepta explícitamente que los niños adquieran la condición de desocupados. Complementariamente, el grupo de 15 a 19 años también presenta un comportamiento ascendente en el número de jóvenes que buscan empleo y confirma el grave problema del desempleo juvenil. En Pereira y Manizales pasaron de 8 mil en 1986 a casi 10 mil en 1996, siendo éste, en consecuencia, el grupo que merece una atención mayor de las autoridades, pues es el que proporcionalmente aporta la mayor cantidad de desempleados: su participación en el total de desempleo fue del $16 \%$. A su turno la tasa específica de desempleo en este grupo de edad se mantuvo en el 3\% en los últimos diez años.

Ahora bien, la lectura de la información sobre el desempleo con perspectiva de género muestra que al nivel nacional urbano las mujeres que buscan trabajo crecen en mayor número al de los hombres. Para Manizales - Pereira, en los grupos de edades menores de 19 años, se observa una leve disminución de las mujeres que buscan trabajo, quizás como una consecuencia de la ampliación de la cobertura escolar que las ha beneficiado principalmente a ellas. A escala nacional se crece de 68 mil a 70 mil mujeres desempleadas y los hombres mantienen unas cifras similares.

En Manizales, el 36\% de los desocupados tenían a lo sumo estudios de primaria, el 55\% estudios secundarios y el $9 \%$ estudios superiores, presentando una tendencia similar a lo ocurrido en el país. Los niños desocupados entre los 12 y 14 años tenían estudios primarios y los de edades entre los 15 y 19 años se distribuían así: el 52\% presentaban estudios primarios, y el $47 \%$ estudios secundarios.

\section{Conclusiones}

- La tendencia ya generalizada es que se presenten altas tasas de nacimientos en adolescentes menores de 19 años; además cifras proporcionadas por el DANE muestran que 40 de cada 100 escolares y 37 de cada 100 niños menores de 5 años presentan condiciones de desnutrición. Abundan los casos de maltrato infantil y abuso sexual, que afectan sobre todo a los niños de 10 y 14 años.

- La legislación en materia de salud en el caso concreto de la Ley 100, ha dejado a más población sin seguridad en salud; el régimen contributivo ha perdido 64.313 afiliaciones entre 1997 y lo corrido del 2000, el régimen subsidiado ha ganado 6.164 afiliaciones, el seguro social ha perdido 53.791 afiliados, las EPS han perdido 10.552, mientras que la población sin ningún aseguramiento ha crecido en 72.844.

- En materia de seguridad, se observa un incremento en los hechos delictivos, debilidad en las condiciones para afrontar la inseguridad; de hecho la tasa de homicidios ha aumentado especialmente en las comunas 2 y 3 . Además existe un déficit en lo que se refiere a policías y bomberos en caso de presentarse desórdenes o disturbios en el orden público.

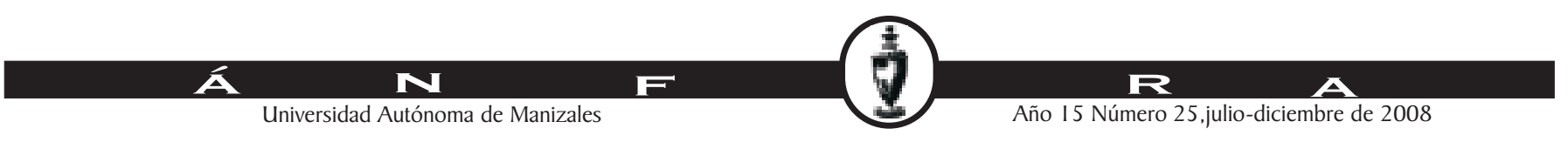


- Más del $70 \%$ de la población y las viviendas pertenece a los estratos bajos, mientras que el $40 \%$ de la población pertenece al estrato 3. Cuando se habla de un elevado porcentaje de las viviendas pertenece a los estratos bajos, se refiere a que una gran proporción de la comunidad vive en hacinamiento crítico.

- Desde el punto de vista de Amartya Sen, se concluye que el número de opciones que las personas tienen y la libertad de elección sobre estas opciones también contribuye al bienestar humano. De esta forma, desde el enfoque de las capacidades se postula que más libertad y más capacidad de elección, tiene un efecto directo sobre el bienestar incrementándolo.

- Según el Informe de Desarrollo Humano para el eje cafetero, elaborado por el PNUD, es evidente el deterioro de los índices para Caldas, y cómo día tras día se va en retroceso, pues el nivel de este índice en el 2002 fue prácticamente igual al de 1993. Según este informe, es deprimente saber cómo el período comprendido entre 1993 - 2003 ha significado una década perdida en cuanto a desarrollo social.

- Es importante señalar que la población que más padece la situación de pobreza extrema, son las personas en situación de desplazamiento forzado interno. Este grupo en su mayoría compuesto de jóvenes y niños, así como de mujeres cabeza de hogar, padecen malnutrición, enfermedades inmunoprevenibles y mentales, falta de ingresos y exclusión social. La paradoja es que, más de la mitad de estas familias son propietarias o cultivadoras de parcelas productoras de alimentos, ahora abandonadas.

- Debido a la exclusión social que ha debido soportar la mujer a través de la historia, en unas sociedades más que en otras, y a la miopía del Estado en el apoyo a las funciones de la mujer como dar a luz, asegurar la alimentación de la familia y en especial la de la nueva generación, se debe comprender en qué medida, dichas funciones constituyen la raíz misma de los problemas sociales, que por estar definidos a menudo en términos agregados, tienden a pasarse por alto cuando se determinan los puntos cruciales en los que tiene que intervenir el Estado y la Comunidad Internacional.

- Los hombres y mujeres entre 12 y 24 años de edad que apenas representan el $36 \%$ de la fuerza laboral, contribuyen con un $62 \%$ de los cambios en el empleo ocasionados por variaciones en la demanda agregada. Esto quiere decir, que se debe hacer principal hincapié en la formación de los niños, niñas y jóvenes de la ciudad, para que además de encontrar empleo en la ciudad, lo hagan en trabajos de calidad que impliquen una mejora sustancial en el ingreso, y no sólo en empleos que permitan satisfacer las necesidades básicas.

- Se siguen observando diferencias entre niñas y niños en la ciudad de Manizales, principalmente en el nivel de secundaria, donde 74 de cada 100 niños tienen la oportunidad de ir al colegio, mientras que sólo 68 de cada 100 niñas lo pueden hacer.

- En Manizales, hay un importante porcentaje de hogares ubicados por debajo de la línea de pobreza $42 \%$, el cual es incluso superior al registrado en el resto de áreas metropolitanas del país 38\%. Esto indica, entre otras cosas, que si Manizales quiere cumplir la meta de reducción de la pobreza a la mitad hacia el año 2015,

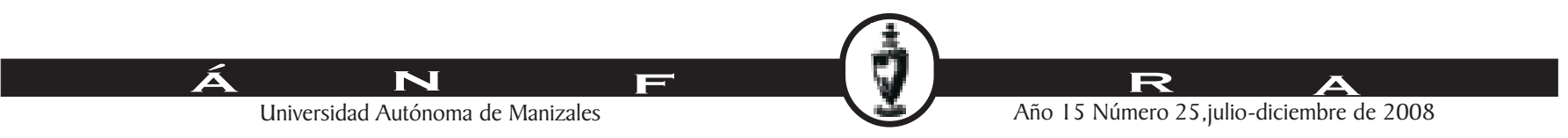


deberá hacer ingentes esfuerzos en la estabilidad económica, para que se propicien nuevos espacios de concertación civil, donde se hallen oportunidades de empleo gratificante, tanto a nivel de ingresos, como de capacidades y tiempo, que permita tener núcleos familiares incorporados al tejido social de la ciudad.

- Según el Banco Mundial la proporción de la población global que vive en la extrema pobreza se podría reducir a la mitad para el 2015, según lo previsto en los objetivos del milenio. Si la tasa media de crecimiento del producto interno bruto per cápita de los países en desarrollo fuese de $3.6 \%$ al año durante los próximos quince años para reducir a la mitad la proporción de personas desnutridas y mal nutridas, para el 2015 se precisará la acción concertada de los países afectados y la comunidad internacional.

- De acuerdo con la encuesta nacional de hogares del DANE, en los últimos cinco años han salido de Manizales un total de 10.604 personas, de los cuales: el $9 \%$ son menores de 12 años y el $91 \%$ son mayores. En cuanto a su formación académica, se encuentra que el $4 \%$ de ellos son analfabetas; El 54\% sólo tiene nivel de primaria, el $31 \%$ secundaria y sólo el $11 \%$ tiene educación superior. Así mismo, se encuentra que durante los últimos cinco años, 23.408 personas de otras partes del país tomaron residencia en la ciudad de Manizales. A diferencia de los emigrantes, los niveles de capital humano de esta población son buenos, pues sólo el 3\% son analfabetas, una cuarta parte tiene nivel de primaria, $46 \%$ tiene secundaria y un $23 \%$ tiene educación superior.

\section{Recomendaciones}

- Recientes estudios plantean que la pobreza del Eje Cafetero es causa de la migración desordenada, Además, aseguran que las condiciones de vida determinan en buena parte la intencionalidad migratoria regional, pero las condiciones reales de esa migración hacen inestables las familias en lo económico, social, e intrafamiliar. Aunque algunos analistas han propuesto recuperar el crecimiento económico con una reconversión productiva de economía cafetera e integración regional con proyectos concertados, política educativa y seguridad alimentaria, es poco lo que se ha hecho en estos campos, por lo cual se recomienda diseñar políticas y aplicarlas con el fin de solucionar este problema.

- En Manizales las manifestaciones de pobreza son claras: la prestación de servicios básicos de infraestructura urbana continúa siendo precaria, el $20 \%$ de la población de Manizales no cuenta con abastecimiento de agua potable y el servicio de alcantarillado sólo beneficia a 7 de cada 10 personas, existe una tendencia a la inequidad que se refleja en el desnivel de los ingresos y una mayor concentración de la riqueza, el declive de los ingresos está aumentando cada vez más, los salarios reales han disminuido y el desempleo es ahora mayor que en los años noventa. Los problemas que generan la pobreza en Manizales, requieren procesos socioeconómicos alternativos que valoren las estrategias vinculadas a prácticas sostenibles. Se recomienda pensar y repensar la política social que se ha venido implementando en la ciudad de Manizales con el fin que se mejoren todas las situaciones, o por lo menos algunas de las enumeradas anteriormente.

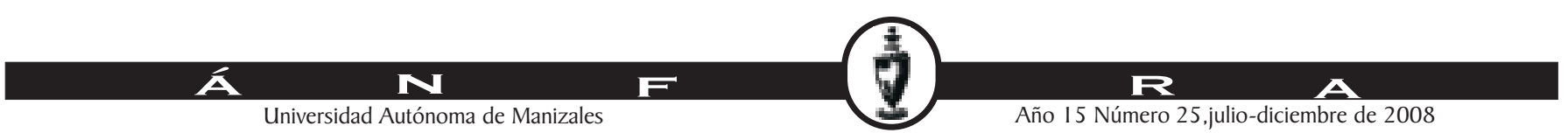


- Es evidente que para lograr los cambios necesarios que aporten a la reducción del deterioro de los índices de desarrollo social, se debe contemplar la necesidad de realizar transformaciones importantes en el modelo de desarrollo, donde haya participación activa tanto del sector público como del sector privado, incorporar el conocimiento como factor más importante de la actividad productiva y la educación como la base principal para reducir los índices de pobreza, pues la diferencia mundial ya no está entre los que tienen y no tienen, sino entre los que saben y no saben.

- Se requiere aunar esfuerzos muy precisos, en los temas de la reducción de la pobreza, la universalización de la educación primaria, reducción de la desnutrición infantil y de la mortalidad materna, cambios institucionales. Para lograr estos objetivos, se necesita un compromiso serio por parte de los gobiernos e instituciones que son quienes lideran los cambios sociales por medio de la inversión social y la reestructuración con el fin de lograr un desempeño eficiente en la prestación de los servicios públicos. Pero es lamentable, cómo en los planes de desarrollo quedan planteadas todas las necesidades de una comunidad entera y cómo no se reúnen esfuerzos para contribuir al cambio que todos estamos esperando, en lugar de reducir los índices de pobreza, lograr mayor cobertura y mejorar educación, prestar un mejor y más amplio servicio de salud, tener oportunidades de empleo, reducir las tasas de desocupación.

- Según las estadísticas en el año 2002 hubo 150 millones de niños malnutridos menores de 5 años en los países en desarrollo; si continua el ritmo actual de reducción, seguirá habiendo 140 millones de niños con peso inferior al normal en el 2020. Se recomienda trabajar políticas públicas para mejorar esta situación, en especial para la ciudad de Manizales.

- Por último, y teniendo en cuenta que para alcanzar el primer objetivo trazado para el milenio, reducir la pobreza a la mitad, se debe mirar ésta de manera amplia y no únicamente como el número de personas que tienen un ingreso menor a un dólar por día, se puede decir que Manizales está lejos de alcanzarla integralmente, ya que, como se dijo antes, los datos pueden variar drásticamente según la metodología que se use; en las que se encuentran cifras alentadoras para cualquier lector desprevenido, sin embargo, Manizales sigue siendo, como hace ya muchos años, una ciudad con una realidad distinta a la evidenciada en las cifras señaladas, una ciudad marcada por el tradicionalismo, con necesidades urgentes para niños y jóvenes, que no encuentran espacios en su cotidianidad que les permita desplegar todas sus capacidades para desarrollarse como individuos productivos para la sociedad del siglo XXI.

\section{Bibliografía}

ALCALDÍA DE MANIZALES. (2003) "Situación de Salud en Manizales: Indicadores Básicos 2002". Secretaria de Salud y Seguridad Social.

ASOCIACIÓN COLOMBIANA DE LA SALUD -ASSALUD Y FUNDACIÓN FES. LaS Implementaciones de la Ley 100. Un reto. Logros, dificultades, informe de avance. SantaFé de Bogotá. 1997.

Boletín de la Oficina. Sanitaria Panamericana. Actividades sobre Seguridad Social en América Latina. Vol. 115. No 6. 1993.

\section{A N Universidad Autónoma de Manizales}


CENDEX, FUNDACIÓN CORONA Y FUNDACIÓN FORD. Entorno, aseguramiento y acceso en el régimen subsidiado en Colombia. Estudios del caso. SantaFé de Bogotá. 1999.

COLCIENCIAS. Salud para la calidad de la vida. Bases para un plan del programa Nacional de Ciencias y Tecnología de la Salud. Tercer Mundo Editores. 1993.

CORPORACIÓN AUTÓNOMA REGIONAL DE CALDAS. Subdirección Planeación y Sistemas. En, Documento. Agenda para la Gestión Ambiental del Municipio de Manizales, 2002. $181 \mathrm{p}$.

CRECE. (2005) "Boletín de Coyuntura" Observatorio de competitividad de Caldas.

Disponible en:

http://www.recintodelpensamiento.com/crece/docs/mensuales/2005/Boletin\% 20co

yuntura\% 20enero\% 202005.pdf

CRECE. (2002) "I nforme de la Coyuntura" Observatorio de competitividad de Caldas.

Disponible en: http://recintodel pensamiento.com/crece/docs/anuales/2002. pdf

CRECE. (2000) "Informe de Coyuntura" Observatorio de competitividad de Caldas.

Disponible: http://www.recintodelpensamiento.com/crece/docs/anuales/2000.pdf

DANE. Boletín Estadístico de Salud en Caldas 1993 y 1995.

Departamento Administrativo Nacional de Estadística. Los indicadores de Necesidades Básicas Insatisfechas (NBI). En, Boletín de Estadística No 507. Santafé de Bogotá, 1995. $196 \mathrm{p}$.

EL COLOMBI ANO. Pueblos Hoy. Domingo 3 de marzo de 2002. Pág. 14a .

GI RALDO, Luisa Fernanda. (1999) “Estudio de caso Crianza con Cariño. Universidad de Caldas". Centro de Investigación en Familia. Manizales. Disponible en: www. fundacioncorona.org.co

GOBERNACIÓN DE CALDAS, Departamento Administrativo Nacional de Estadística (DANE), Sociedad de mejoras publicas de Manizales. Análisis Demográfico y diagnostico Social de Caldas. Editorial Blanecolor Ltda. Manizales Diciembre 2002.

GOBERNACIÓN DE CALDAS, Secretaria de Integración y Desarrollo Social Unidad de Juventud Palacio Departamental. En, Revista. Política Pública de Juventud. Departamento de Caldas. Manizales. 2003.

HERNÁNDEZ L, Diego Fernando, MANRIQUE ARROYAVE, Adriana, VERA ÁLVAREZ, Gloria Elena. Diagnostico del sector salud en Manizales, Chinchiná, Neira, Palestina y Villamaría. Facultad de Ingeniería Industrial. 1985.

INSTITUCIÓN UNIVERSITARIA TECNOLÓGICA DE BOLÍVAR. Anuario de investigaciones. Cartagena, 1999.

JARAMILLO, Eduardo León. (1995) “Morbimortalidad materna en el Hospital de Caldas, Manizales".

Disponible en: http:// www.colombiamedica. univalle.edu.co

LASSO, Francisco J avier. (2002a) "Economías de Escala en los hogares y pobreza" DNP, Archivos de Economía. Documento 212.

Disponible en: http://www.dnp.gov.co

LASSO, Francisco Javier. (2002b) “Nueva metodología de Encuesta de hogares: ¿Más o menos desempleados?". DNP, Archivos de Economía. Documento 213, 30 de Noviembre de 2002b. Disponible en: http://www. dpn.gov.co LEY 100/93, ESTATUTO DE SEGURIDAD SOCIAL Y DE PENSIONES.

LÓPEZ, Hugo, (2005) "¿Cuántos son los pobres en Colombia?". Seminarios y Conferencias MERPD. Disponible en: http://www. banrep.gov.co

MINISTERIO DE EDUCACIÓN NACIONAL. (2004) Perfil del sector educativo departamento de Caldas: Municipio Certificado de Manizales. República de Colombia. MINISTERIO DE TRABAJO Y SEGURIDAD SOCIAL. Una política de Seguridad Social. Bogotá 1971.

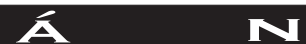

Universidad Autónoma de Manizales 
NÚÑEZ, J airo y SÁNCHEZ, Fabio J osé. (1999) “Estimaciones trimestrales de la línea de pobreza y sus relaciones con el desempeño macroeconómico colombiano (19771997)". DNP, Archivos de Economía. Documento 110. Disponible en: http://www.dpn.gov.co

NÚÑEZ Jairo y BERNAL, Raquel. (1998) “El Desempleo en Colombia: Tasa Natural, Desempleo Cíclico y Estructural y la Duración del Desempleo". Disponible en: http://www.dpn.gov.co

NÚÑEZ, Jairo y ESPINOSA, Silvia. (Sin Fecha) “Determinantes de la Pobreza y la Vulnerabilidad". MERPD. Disponible en: www.dpn.gov.co

PNUD. (2000) "Informe de Desarrollo Humano para Colombia 2000". Disponible en: http://www.pnud.org.co/Informes/IDH-COL-2000.pdf

PREAL. (2004) "Situación Educativa de las Regiones de Colombia". Informe De Progreso Educativo. CINDE. Disponible en: http: //www. preal.org/Documentos/Informe\%20Caldas.pdf

RAMÍ REZ, Néstor Eugenio. (2002) “Programa de Gobierno". (2002-2005) Disponible en: http://www.alcaldiamanizales.gov.co Revista Antioqueña de Economía y Desarrollo. La reforma a la Seguridad Social. No 43. Enero- Abril de 1994.

Revista de investigaciones. Situación y perspectivas de la _Seguridad Social en Colombia. Año 7 Vol. 6. No 1. Nariño. 1993.

Revista el Comercio Exterior. Pobreza y políticas. J unio de 2003, Vol.6. México

Revista Estrategia. El régimen de Seguridad social en Colombia. Octubre 15 de 1996.

Revista Facultad de Salud Pública. Relaciones entre salud pública, seguridad social y funcionalidad del estado, Vol. 13.

SÁNCHEZ, Fabio, (1999) "La medición de la pobreza en Colombia". PND y BID. Disponible en: http://www.iadb.org/regions/re3/pobreza.pdf

SECRETARI A DE SALUD Y SEGURIDAD SOCIAL DE MANIZALES. Revista "Sin Barreras". Año 2. No2. Manizales 2001.

SEN. Amartya K. BRUNDTLAND, Gro Harlem. Banco Interamericano de Desarrollo. Departamento de Desarrollo Sostenible. División de Desarrollo Social. En, Documento. Romper el Ciclo de la Pobreza I nvertir en la I nfancia. Conferencia Magistrales.

SEN, Amartya. (2000) "Las distintas caras de la pobreza". Article publicat a El País, 30 d'agost del 2000. Disponible en: http://www. noucicle.org/arxiu/caraspobr.html

SERVICIO DE CALDAS. Análisis seccional del sector. Plan de Salud 1984-1986: Objetivos y Estrategias. Manizales, 1983.

SISTEMA DE NACIONES UNIDAS Y CEPAL. DNP/PNUD. Agencia Colombiana de cooperación Internacional, Federación colombiana de Municipios y la Cooperación Técnica Alemana. Las regiones Colombianas Frente a los Objetivos del Milenio. Colombia 2004.

UNIVERSIDAD DE CALDAS - SECRETARIA DE SALUD- BENEFICIENCIA DE MANIZALES - SERVICIO DE SALUD. Plan para la Erradicación de la Pobreza Absoluta en la ciudad de Manizales. Salud básica para todos. Sistema de Atención primaria, Manizales, 1997.

VELÁSQUEZ B., Luz Stella. (2003) “Propuesta de una metodología de planificación para el desarrollo urbano sostenible y diseño de un sistema de evaluación de la sostenibilidad de ciudades medianas de América latina". Tesis Doctoral. Barcelona, octubre de 2003. Universidad Politécnica de Catalunya. Disponible en: http://www.tdx.cesca.es/TDX-0630104-141737/

VÉLEZ, Carlos Eduardo. (2002) "Colombia Poverty Report". Document of the World Bank, Volume I. Marzo, 2002. Disponible en: www.dnp.gov.co

http.//www. anec .org.co/revista/articulos. htm? $x=12781 \& c m d \% 5 b 111 \% 5$ d $=c-1-57$

http:// www. camaradirecta.com/webccb/temas/salud/boot/abajo\% 20salud. htm-19k-

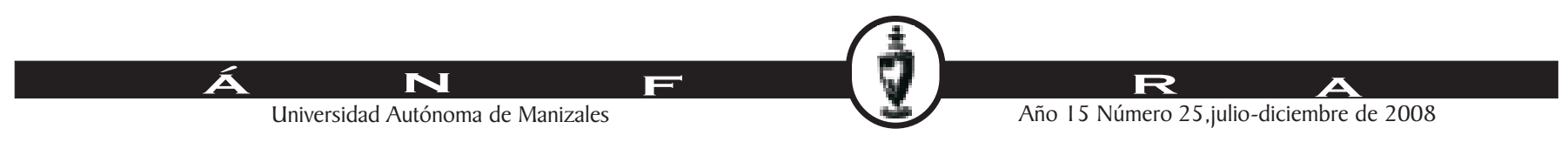


48 Artículo de Investigación

http://www.cgh.org.co/articulos pdf/articulos. php?cat $=13 \&$

http://www.choike.org/nuevo/informes/409.html

http://www.cinde.org.co/constructores_de_paz.htm

http://www.colombianostrabajando.sena.edu.co

http: // www.cut.org.co Central Unitaria de Trabajadores en Colombia.

http://www.derechoshumanos.gov.co/observatorio/04_publicaciones/tm

http://www.elcolombiano.com.co

http://www.gobernaciondecaldas.gov.co/manizales

http: // www. ins.gov.co Instituto Nacional de Salud.

http:// www.javeriana .edu.co/biblos/revista/salud/pdf-revista

http://www.larepublica.com.co

http://www. medicentro.com.co

http: //www. minsalud.gov.co

http://www.moir.gov.co 